\title{
Neurological disorders, genetic correlations, and the role of exome sequencing
}

\author{
Tony L Brown ${ }^{1 *}$ and Theresa M Meloche ${ }^{2}$ \\ ${ }^{1}$ Columbia University, USA \\ ${ }^{2}$ Advanced Research and Human Development Institute, USA
}

\begin{abstract}
Genomic information access and utilization by researchers and clinicians have barely begun the journey for fulfillment of their full potential in the research and clinical arenas. Exciting is the potential depth and breadth of research, clinical applications, and more personalized medicine, that remain on the horizon. Exome sequencing has clarified the responsibilities of over 130 genes, greatly expanding the medical genetics database and enabling the development of orphan diseasebased pharmaceuticals. The focus of our research efforts was to review several literature sources related to rare genomic disease research and exome sequencing, as well as to review the new research and diagnostic strategies that were utilized. Using a systems approach, under discussion are neurology, neuropathy, and the central nervous and musculoskeletal systems. Also discussed will be the topics of inborn errors of metabolism, and the genetic targets related to developmental delay. Recommendations for future research will also be discussed.
\end{abstract}

\section{Exome sequencing}

\section{A review of new strategies for rare genomic disease research}

This literature review will examine several publications in which the authors demonstrate the success of whole exome sequencing (WES) in circumstances where traditional methods have presented ambiguous interpretations or failed altogether, for instance, single -subject populations, large candidate counts and reduced reproductive fitness [1]. By supporting exome sequencing, we will show that there is an increasing need for polymorphism databases and assay strategies that do not depend on positional information, if genomic medicine is to advance its research and clinical utility. Within our review, we will discuss the research related to neurology, neuropathy, the central nervous system, the musculoskeletal system, inborn errors of metabolism, and the genetic targets related to developmental delay. Recommendations for future research will also be discussed.

\section{Disease survey}

\section{Neurology}

Positional cloning techniques have thus far unveiled 19 contributory genes in the study of 31 genetic variations of autosomal dominant spinocerebellar ataxia [2]. The method has yet to overcome the challenges that presented, such as phenotypic and biological manifestations which do not correlate well to molecular mutations due to the exceedingly complex nature of the brain. Exome sequencing has, however, shed additional light on causal mutations for sensory motor neuropathy with ataxia [3], which presents with cerebellar dysfunction, Spinocerebellar Ataxia with Psychomotor Retardation [4], and Spastic Ataxia-Neuropathy syndrome that manifested with remarkable variety between two brothers [5] due to different mutations in the same protease subunits.

A United States incidence of 1 in 12,500 live births makes neuronal ceroid lipofuscinoses the most common group of inherited neurological degenerative disorders [6]. Whether examining the mitochondrial defect implicated in prenatal ventriculomegaly [7], the often early-stage atypical presentation of neurocanthocytosis [8], or the fatal amyotrophic lateral sclerosis [9], scientists recognize that exome sequencing "potentially widens the clinical spectrum associated with Amyotrophic Lateral Sclerosis (ALS) to include bone dysfunction and myopathy, and provides further insight into the importance of cellular protein degradation pathways...." [9].

Unable to identify a contributory mutation by using traditional polymerase chain reaction (PCR)-sequencing in their study of the brain demyelinating disorder called $\mathrm{X}$-linked leucoencephalopathy, a group of researchers subsequently applied exome sequencing to only one lane of material and obtained enlightening results [10]. The disorder affects myelin - the material responsible for brain matter being designated as white matter instead of grey. Although the lack of nerve myelination normally leads to central and peripheral nervous system disturbances, such as motor deterioration, it is notable that another research group used various techniques in conjunction with exome sequencing to identify the variant -- hypomyelinating leukoencephalopathy in three individuals who could walk without support [11].

The cortex of the human brain is composed of a complicated landscape of convolutions, the biological formation of which is controversial. Exome sequencing was used to "present conclusive

Correspondence to: Tony L Brown, Columbia University, USA, E-mail: tbrown@post.harvard.ed

Key words: genomics, exome sequencing, rare disease, genetics, genome, diagnosis, personalized medicine

Received: January 25, 2016; Accepted: February 16, 2016; Published: February 19,2016 
genetic evidence that recessive LAMC3 mutations cause human occipital cortical malformations characterized by complex gyration abnormalities and challenge the concept that cortical smoothening needs to be caused by disruption of early events in cortical neuronal migration exclusively" [12]. A Yale study that also used exome sequencing to study the same subject concluded that the attained results "demonstrate that this technology will be particularly valuable for gene discovery in those conditions in which mapping has been confounded by locus heterogeneity and uncertainty regarding the boundaries of diagnostic classification, pointing to a very bright future for its broad application to medicine" [13].

A successful exome sequencing study of the prenatally-fatal neurological condition known as Fowler syndrome prompted the investigators to announce their opinion that "this genetic approach is a much simpler and faster approach than traditional homozygosity mapping that makes full use of emerging technologies and is capable of identifying rare or common monogenic, recessive disorders" [14]. This may be especially important in the attempt to diagnose brain formation disorders such as polymicrogyria, which is currently diagnosed by cranial magnetic resonance imaging [15]. spastic paraparesis, a presumed ion channelopathy identified via loss of function predictions [16], and the most common paroxysmal movement disorder, paroxysmal kinesigenic which is often clinically misdiagnosed as epilepsy [17].

Exome sequencing was also successfully used to study migraine headaches in which there was no aura (MWO), the most common type of migraine headache among the afflicted migraine-suffering population $(n=4)$, and during which there were six [(EDA2R $(G 170 A)$, UBE2NL (T266G), GBP2 (A907G), EMR1 (C264G), CLCNKB (A1225G), \& ARHGAP28 (C413G)]novel rare non-synonymous mutations identified [18]. These researchers focused on a very small control group of four unrelated people who were not migraine sufferers, the results of which were studied in comparison to the four -member sole family migraine group in which each participant had the MWO affliction. Angiogenesis, cortical spreading depression, and trigeminovascular reflex theories each were supported by, or consistent with, MWO susceptibility under the currently supported theory of multi-gene predisposition. Additionally, the $\mathrm{X}$-chromosome location of the EDA2R and UBE2NL mutations were reported to support gender difference predisposition [18].

The chromosome 14 PRIMA1 gene novel splice site mutation $($ c. $93+2 \mathrm{~T}>\mathrm{C})$ was demonstrated in a mini -gene analysis of two siblings as having led to "skipping of the first coding exon of the PRIMA1 RNA..." [19]. Research findings in the 300 nocturnal frontal lobe epilepsy subjects who were also studied, did not reveal further PRIMA1 mutations. The authors concluded that the likely causative factor in severe nocturnal frontal lobe epilepsy was an intensification of cholinergic responses.

\section{Neuropathy}

Researchers investigating the peripheral neuropathy of CharcotMarie- Tooth (CMT) disease, the most common inherited muscular disorder [20], were faced with a population of 40 candidate genes and asserted that "linkage analysis followed by candidate gene Sanger sequencing, utilized in other studies would...have required the sequencing of at least the 78 exons" [21]. Utilizing exome sequencing, the scientists were able to rapidly identify the disorder in a previously undiagnosed family and consequently take the position that their accomplishments "support the notion that genomic approaches in the form of targeted resequencing or whole- genome sequencing will replace traditional medical genetic testing in the near future" [22]. Recently, whole exome sequencing was utilized to newly identify the p.I43N mutation in CMT disease in a family whose members exhibited autosomal dominant demyelinating CMT neuropathy [23]. Having performed subsequent research on transgenic mice, these authors concluded that there might be an implication by their data findings that "overexpression of wild type as well as mutant PMP2 also causes the CMT1 phenotype, which has been documented in the PMP22" [23]. Kennerson et al. studied 67 families for whom there already had been a probable suspicion of X-linked CMT [24]. In the latter study, the researchers found clinically, electrophysiologically, and via neuroimagery, that "the p.R158H PDK3 mutation [findings from a second CMTX6 family] were similar to the axonal neuropathy reported in the [original] Australian family," even though the phenotype and genotype results indicated that the two families had mutations of a different haplotype [24]. Whole -exome sequencing research expanded HSPB8 mutations knowledge, which had previously only associated with either CMT type $2 \mathrm{~L}$ or distal hereditary motor neuronopathy type IIa [25]. These researchers were also able to demonstrate that the eventual outcomes, when early neurogenic effects of HSPB8 mutations were present, were no longer limited to the aforementioned two diseases [25].

\section{Central nervous system}

Nervous system disorders continue to challenge the medical genomics of rare Mendelian mutation identification. Two examples in which exome sequencing has proven successful are the new neuroectodermal CHIME ( $C$ oloboma, $H$ eart defects, Ichthyosiform dermatosis, Mental retardation, Ear anomalies with hearing loss) syndrome that is "presumed to be an autosomal recessive disorder because of recurrence in sibs" [26], and the Joubert syndrome, a disorder in which, for the majority of subjects, "the causal mutations have not yet been identified..." [27]. The recent 2015 French Canadian population study that utilized a combined targeted and exome sequencing approach successfully identified two non-French Canadian subjects with the CEP104 mutations of Joubert syndrome and demonstrated a $94 \%(n=43)$ prevalence of CEP104 disruption as conclusive evidence of causation "despite substantial locus and allelic [population] heterogeneity" [28].

Kohlschutter-Tonz syndrome is another example in which researchers are using exome sequencing to shed light on disorders for which "the molecular basis has not yet been elucidated" [29]. Such is also the case regarding what researchers described as "a new lethal autonomic sensory neuropathy" [30] and the incompletely understood brain malformation disorder Baraitser-Winter syndrome [31].

We find an ambitious application of exome sequencing in the molecular research area dedicated to mental retardation. A letter published by Nature Genetics focused on researchers' assertion that "de novo mutations may compensate for allele loss due to severely reduced fecundity in common neurodevelopmental and psychiatric diseases, explaining a major paradox in evolutionary genetic theory" [32]. Based on exome sequencing -based application of their theory, the investigators further claimed that "together with de novo copy number variation, de novo point mutations of large effect could explain the majority of all mental retardation cases in the population" [32].

Early infantile epileptic encephalopathy was studied $(n=48)$ utilizing a SureSelectXT custom multiple encephalopathy/developmental delay gene panel, the results of which were determined to have identified 
GABRB3 mutations as the causative factor(s). Identified during this research study was c.860C $>\mathrm{T}$ (p.Thr287Ile), described as a novel $d e$ novo GABRB3 heterozygous missense mutation and implicated as an emerging causative factor in early-onset epilepsy [33].

Defective selenocysteine biosynthesis was the conclusion in a study whose design was to potentially identify a genetic molecular basis for progressive encephalopathies with CSF or serum lactate elevation [34]. These researchers were successful in identifying new phenotypes for both a missense (p.Thr325Ser) and a nonsense (p.Tyr429*) mutation in their study that of three families, each of whom had a neuropathological presentation of laminar necrosis, severe myelin loss, neuron loss, and astrogliosis. These mutations had been associated with progressive cerebellocerebral atrophy, which resulted in reduced, but still measurable, selenoprotein levels, as well as quantifiable brain oxidative protein damage in the study subjects.

\section{Musculoskeletal}

Musculoskeletal disorders (MS) affect up to $33 \%$ of adults in the United States [35]. The tendency of these disorders to worsen with age, combined with the significant number of citizens approaching geriatric age, indicates that we can reasonably expect a statistical escalation in the near future. By exposing previously unidentified therapeutic targets in MS disorders such as Osteogenesis imperfecta [36], Skeletal Dysplasia [37], and Primary Hypertrophic Osteoarthropathy [38], deciphering of the exome sequencing has a promising role in the development of new treatment modalities. Researchers asserted the utility of exome sequencing in "the diagnostic algorithm for infants presenting with congenital dislocations, chondrodysplasia, and short stature" [39]. Exome sequencing may prove equally valuable in early screening for heritable, but poorly understood, conditions such as metachondromatosis [40], Hajdu-Cheney [41], Early Onset Generalized Dystonia [42], Distal Arthrogryposis Type 1 [43], and Nager syndrome [44].

Researchers from the Kennerson study on CMT type 6 confirmed that muscularly, MRI results revealed lower extremity distal muscle fatty infiltrates and that the majority of the infiltrates noted were in the soleus muscles, with lesser fatty deposition in the tibialis anterior muscles. The latter study's authors concluded that the finding "differs from demyelinating CMT1A patients and is similar to axonal CMT2A patients" [24]. Autosomal dominant distal neuromuscular disease research on HSPB8 mutations as the causal factor that resulted in myofibrillar aggregates and rimmed vacuolar myopathy combined with neurogenic changes revealed by MRI that the lower limb diffuse tissue alterations in the early disease stages eventually progressed in later stages to myopathy with a typical fatty deposition [45].

\section{Genetic targets related to developmental delay}

Successful identification of the Schinzel-Gideon syndrome allele underscores the idea that, while "Protein coding genes constitute only approximately $1 \%$ of the human genome but harbor $85 \%$ of the mutations" [46], they need not remain unidentified. Developmental delay -related genetic targets such as non- syndromic mental retardation [47], mental retardation [32] and sporadic autism spectrum disorders characterize novel candidates for identification by whole exome sequencing, even when complicated by consanguinity [48] and de novo occurrences [49]. It is not uncommon for diseases seemingly unrelated by signs, symptoms or phenotype to share a common molecular mechanism or pathway. Examples are the monogenic comorbidities of the neurodevelopmental disorder autism such as Rett Syndrome and
Fragile $\mathrm{X}[50,51]$. It was especially useful however, to find common genes connecting cancer and autism. Specifically, TSC2, NF1, and TSC1 gene mutations intensify the cancer predisposition in autism patients. Moreover, because common genomic pathways suggest common treatment targets, exome sequencing empowers drug research with a multifaceted approach. Since exome sequencing, together with genome-wide-association studies and other modalities have recently uncovered the polygenic nature of autism [52], this leaves wide open the possibility of therapeutic advances in several diseases.

Whole exome sequencing has begun to gain utility as an affordable clinical biomarker. A study of 50 patients at the Radboud University Medical Centre Nijmegen concluded that WES "has a higher yield and lower costs to provide a diagnosis in child presumed to have a genetic origin of their disease" [53]. The margin of savings was not trivial, reported cost for WES $€ 3,600$ compared to $€ 12,241$ for the non-WES care. A neurogenetics clinic went further by conducting a retrospective cohort study on patients with neurodevelopmental disabilities whose non-WES evaluations had yielded unactionable or inconclusive results. Presentations, new WES -informed diagnoses and subsequent changes in treatment plans were tracked for the 78 patients. The investigators concluded that "the high diagnostic yield of WES supports its use in pediatric neurology practices. It may also lead to earlier diagnosis, impacting medical management, prognostication, and family planning. WES therefore serves as a critical tool for the child neurologist" [54].

\section{Cancer}

The Cancer Genome Atlas (TCGA) consortium has used exome sequencing to evolve the decades -long strategy of analyzing melanoma somatic mutation at the at the single gene level. In general, melanomas are of neurologic concern and the related melanocytes arise neural crest cells, which also give rise to neural structures such as the iris, choroid and substantia nigra. The exome - based technique developed by TCGA has generated the largest database to date while elucidating the structure of 333 cutaneous melanomas [55].

As mentioned above, one of the strengths of WES is that is can identify overlapping genes between multiple diseases. Conversely, and equally instructive, WES can highlight diseases that do not share common genes. Chronic lymphocytic leukemia and acute myeloid leukemia are two such examples [56]. Classification of disease subtypes is also useful as it can identify patient-specific genomic rearrangements such as those found in glioblastoma tumors [57].

\section{Inborn errors of metabolism}

The textbook Inborn Errors of Metabolism (1923) is a $20^{\text {th }}$ century publication written by Archibald Garrod, the British physician who also coined the like -worded phrase still in use today. Inborn errors of metabolism (IEM) typically involve a defective enzyme that was supposed to convert one substance into another [58]. Classical categories of the disorder include the deranged metabolism or modification of organic acids, carbohydrates, amino acids, or lysosomal storage components. Technological developments such as exome sequencing, however, have enabled the expansion of these categories.

We found an important example in the elucidation of what researchers describe as "a previously undescribed, severe IEM shedding light on a functional link between the methionine cycle and adenosine metabolism" [59]. Combined Malonic and Methylmalonic Aciduria is a disorder of excess acid in the blood involved in failure to thrive, B-12 malabsorption, immunodeficiency, seizures, and possible death. 
The treatments for this disorder can vary, and is based on the specific offending amino acid mutation. Exome sequencing has contributed to the discovery of an increasing number of variants [60,61].

\section{Future research}

Future research opportunities to explore exome sequencing are abundant. There is a dearth of clinical information for the endocrine, renal, reproductive, urinary, and respiratory systems, as well as research related to connective tissue. An exceptional opportunity exists for sentinel research and also for further exploration into the world of exome sequencing as it relates to rare genomic diseases. Alzheimer's disease is one of the most exciting areas of research focus that can be boosted by exome sequencing. The TOMMORROW Trial of AD-4833 for the Delay of Onset of Mild Cognitive Impairment Due to Alzheimer's Disease in Subjects Selected Using a Genetic- Based Biomarker Risk Assignment Algorithm TOMMORROW study is currently in clinical trials and based on the theory that a molecule called apolipoprotein E (ApoE) regulates both Amyloid -B deposition and ApoE repair mechanism for neurons under stress. Relatedly, the TOMM40 gene contains a non -coding stretch of DNA on chromosome 19 adjacent to APOET. The aim is to find a common thread while genotyping these two entities that may lead to a common treatment. For example, the study hypothesizes that the type 2 diabetes treatment pioglitazone may also be prescribed to those with an Alzheimer Disease predisposition in order to delay the onset of the disease [62]. Exome sequencing might also facilitate research around the biophotonic biomarkers of Alzheimer's disease by mitigating the enormous number of targets investigated by the modality [63].
Several studies discussed had an extremely limited subject focus. We suggest that there needs to be significantly larger population participants in exome sequencing research, not only to further this area of medicine but also to be more applicable to a greater portion of the general population in which the same, or similar, mutations might exist. The mutations related to migraine without aura, for instance, offer significant opportunity for future research that should focus not only on a much larger population for both the MWO group, but also the control group. We suggest that, given the historical knowledge that females are overwhelmingly represented in the MWO population, near -future exome sequencing research should focus on gender differences as they relate to MWO predisposition. Early- onset (infantile) epilepsy is another area in which research focus should be specifically related to an age-based population, both for further case identification and for BRBR3-related genotype and phenotype delineation [19]. We suggest that early studies also lean toward identification of any gender predisposition.

Exome sequencing may also be useful in the differential diagnosis of neuropsychiatric conditions. For instance, nightmares, sleep walking and night terrors are currently distinguishable by sleep phase -the first occurring during rapid eye movement and the latter two during slow wave delta sleep. Diagnostic sensitivity might be increased by research targeted at the common genetic predisposition sleepwalking and night terrors [64]. Finally, although we have only reviewed the utility of exome sequencing in the so-called forward direction, we anticipate progress towards reverse phenotyping which would be of great value to the field of personalized medicine. Exome sequencing organizations

Table 1. Exome sequencing organizations.

\begin{tabular}{|c|c|c|}
\hline & Exome Databases & \\
\hline $\begin{array}{l}\text { Alzheimer's Disease } \\
\text { Neuroimaging } \\
\text { Initiative }\end{array}$ & http://adni.loni.usc.edu/ & $\begin{array}{l}\text { Working to define the progression of Alzheimer's disease and to collect, } \\
\text { validate and utilize data such as MRI and PET images, genetics, cognitive } \\
\text { tests, CSF and blood biomarkers as predictors for the disease }\end{array}$ \\
\hline $\begin{array}{l}\text { Alzheimer's Disease Sequencing } \\
\text { Project }\end{array}$ & https://www.niagads.org/adsp/ & $\begin{array}{l}\text { Aiming to develop and execute a large-scale sequencing project to analyze } \\
\text { the genomes of a large number of well-characterized individuals in order } \\
\text { to identify a broad range of Alzheimer's disease risk and protective gene } \\
\text { variants, with the ultimate goal of facilitating the identification of new } \\
\text { pathways for therapeutic approaches and prevention }\end{array}$ \\
\hline Autism Genetic Database & http://wren.bcf.ku.edu/ & $\begin{array}{l}\text { A comprehensive database for autism susceptibility genes and CNVs, } \\
\text { integrated with known noncoding RNAs and fragile sites }\end{array}$ \\
\hline Autism Database & http://autism.mindspec.org/autdb/Welcome.do & $\begin{array}{l}\text { An integrated resource for the autism research community, which is built } \\
\text { on information extracted from the studies on molecular genetics and } \\
\text { biology of autism spectrum disorder }\end{array}$ \\
\hline $\begin{array}{l}\text { Cancer Genome Atlas Genome } \\
\text { Sequencing Centers }\end{array}$ & $\begin{array}{l}\text { http://cancergenome.nih.gov/abouttcga/overview/howitworks/ } \\
\text { sequencingcenters }\end{array}$ & $\begin{array}{l}\text { The Cancer Genome Atlas (TCGA) Genome Sequencing Centers (GSCs) perform } \\
\text { large-scale DNA sequencing using the latest sequencing technologies. Supported by } \\
\text { the National Human Genome Research Institute (NHGRI) large-scale sequencing } \\
\text { program, the GSCs generate the enormous volume of data required by TCGA, while } \\
\text { continually improving existing technologies and methods to expand the frontier of } \\
\text { what can be achieved in cancer genome sequencing. All sequencing data are available } \\
\text { in the TCGA Data Portal or from the TCGA page at NIH's database of Genotype and } \\
\text { Phenotype (dbGaP). }\end{array}$ \\
\hline Exome Aggregation Consortium & http://exac.broadinstitute.org & $\begin{array}{l}\text { A coalition of investigators seeking to aggregate and harmonize exome sequencing } \\
\text { data from a wide variety of large-scale sequencing projects, and to make summary data } \\
\text { available for the wider scientific community. }\end{array}$ \\
\hline $\begin{array}{l}\text { National Database for Autism } \\
\text { Research }\end{array}$ & ndar.nih.gov & $\begin{array}{l}\text { An NIH (USA)-funded research data repository that aims to accelerate } \\
\text { progress in autism spectrum disorder research through data sharing, data } \\
\text { harmonization and reporting of research results }\end{array}$ \\
\hline $\begin{array}{l}\text { National Institute on Aging } \\
\text { Genetics } \\
\text { of Alzheimer's Disease Data } \\
\text { Storage } \\
\text { Site }\end{array}$ & https://www.niagads.org/ & $\begin{array}{l}\text { A national genetics data repository (USA) that facilitates access of } \\
\text { genotypic data to qualified investigators for the study of the genetics of } \\
\text { late-onset Alzheimer's disease }\end{array}$ \\
\hline $\begin{array}{l}\text { NHLBI GO Exome } \\
\text { Sequencing Project }\end{array}$ & http://evs.gs.washington.edu/EVS/ & $\begin{array}{l}\text { Discovers novel genes and mechanisms contributing to heart, lung and blood disorders } \\
\text { by pioneering the application of next-generation sequencing of the protein coding } \\
\text { regions of the human genome. }\end{array}$ \\
\hline
\end{tabular}


have begun to multiply as the science matures (Table 1), and will likely continue to do so for some time.

\section{Summary}

In the investigation of rare congenital diseases, exome sequencing overcomes several interpretation challenges presented to traditional study designs of Mendelian genetics and genomic medicine while contributing clinical utility as a molecular diagnostic tool that can expand disease phenotypes and therapeutic targets. Geneticists traditionally analyze hereditary pedigrees using decision trees established on the observed incidence of mutation for a minority of key subtypes. Consequently, the relative uniform phenotypes of many genetic diseases make it difficult to determine which genes are affected, for example, syndromes with apparent mutation- phenotype disharmony or multigenerational compound heterozygosity.

\section{References}

1. Dolled-Filhart MP, Lordemann A, Dahl W, Haraksingh RR, Ou-Yang C, et al. (2012) Personalizing rare disease research: How genomics is revolutionizing the diagnosis and treatment of rare disease. Personalized Medicine 9: 805-819.

2. Wang JL, Yang X, Xia K, Hu ZM, Weng L, et al. (2010) TGM6 identified as a novel causative gene of spinocerebellar ataxias using exome sequencing. Brain 133: 35103518. [Crossref]

3. Brkanac Z, Fernandez M, Matsushita M, Lipe H, Wolff J, et al. (2002) Autosomal dominant sensory/motor neuropathy with Ataxia (SMNA): Linkage to chromosome 7q22-q32. Am J Med Genet 114: 450-457. [Crossref]

4. Doi H, Yoshida K, Yasuda T, Fukuda M, Fukuda Y, et al. (2011) Exome sequencing reveals a homozygous SYT14 mutation in Adult-Onset, Autosomal-Recessive Spinocerebellar Ataxia with Psychomotor Retardation. Am J Hum Genet 89: 320-327. [Crossref]

5. Pierson TM, Adams D, Bonn F, Martinelli P, Cherukuri PF, et al. (2011) Whole-exome sequencing identifies homozygous AFG3L2 mutations in a Spastic Ataxia-Neuropathy syndrome linked to mitochondrial m-AAA protease. PLoS Genetn 7: 1-10. [Crossref]

6. Benitez BA, Alvarado D, Cai Y, Mayo K, Chakraverty S, et al. (2011) Exome-sequencing confirms DNAJC5 mutations as cause of adult neuronal ceroid-lipofuscinosis. PLoS One 6: e26741. [Crossref]

7. Berger I, Ben-Neriah Z, Dor-Wolman T, Shaag A, Saada A, et al. (2011) Early prenatal ventriculomegaly due to an AIFM1 mutation identified by linkage analysis and whole exome sequencing. Mol Genet Metab 104: 517-520. [Crossref]

8. Walker RH, Schulz VP, Tikhonova IR, Mahajan MC, Mane S, et al. (2011) Genetic diagnosis of neuroacanthocytosis disorders using exome sequencing. Mov Disord 28: 539-543. [Crossref]

9. Johnson JO, Mandrioli J, Benatar M, Abramzon Y, Van Deerlin VM, et al. (2010) Exome sequencing reveals VCP mutations as a cause of familial ALS. Neuron 68: 857864. [Crossref]

10. Tsurusaki Y, Okamoto N, Suzuki Y, Doi H, Saitsu H, et al. (2011) Exome sequencing of two patients in a family with atypical X-linked leukodystrophy. Clin Genet 80: 161166. [Crossref]

11. Saitsu H, Osaka H, Sasaki M, Takanashi J, Hamada K, et al. (2011). Mutations in POLR3A and POLR3B encoding RNA polymerase III subunits cause an autosomalrecessive hypomyelinating leukoencephalopathy. Am J Hum Genet 89: 644-651. [Crossref]

12. Barak T, Kwan KY, Louvi A, Demirbilek V, SaygÄ S, et al. (2011) Recessive LAMC3 mutations cause malformations of occipital cortical development. Nat Genet 43: 590594. [Crossref]

13. Bilgüvar K, Oztürk AK, Louvi A, Kwan KY, Choi M, et al. (2010) Whole-exome sequencing identifies recessive WDR62 mutations in severe brain malformations. Nature 467: 207-210. [Crossref]

14. Lalonde E, Albrecht S, Ha KC, Jacob K, Bolduc N, et al. (2010) Unexpected allelic heterogeneity and spectrum of mutations in Fowler syndrome revealed by nextgeneration exome sequencing. Hum Mutat 31: 918-923. [Crossref]

15. Murdock DR, Clark GD, Bainbridge MN, Newsham I, Wu YQ, et al. (2011) Wholeexome sequencing identifies compound heterozygous mutations in WDR62 in siblings with recurrent polymicrogyria. Am J Med Genet A 155A: 2071-2077. [Crossref]

16. Erlich Y, Edvardson S, Hodges E, Zenvirt S, Thekkat P, et al. (2011) Exome sequencing and disease-network analysis of a single family implicate a mutation in KIF1A in hereditary spastic paraparesis. Genome Res 21: 658-664. [Crossref]

17. Chen W, Lin Y, Xiong Z, Wei W, Ni W, et al. (2011). Exome sequencing identifies truncating mutations in PRRT2 that cause paroxysmal kinesigenic dyskinesia. Nat Genet 43: 1252-1255. [Crossref]

18. Jiang Y, Wu R, Chen C, You ZF, Luo X, et al. (2015) Six novel rare non-synonymous mutations for migraine without aura identified by exome sequencing. J Neurogenet 29 188-194. [Crossref]

19. Hildebrand MS, Tankard R, Gazina EV, Damiano JA, Lawrence KM, et al. (2015) PRIMA1 mutation: a new cause of nocturnal frontal lobe epilepsy. Ann Clin Transl Neurol 2: 821-830. [Crossref]

20. Weedon MN, Hastings R, Caswell R, Xie W, Paszkiewicz K, et al. (2011) Exome Sequencing Identifies a DYNC1H1 Mutation in a Large Pedigree with Dominan Axonal Charcot-Marie-Tooth Disease. Am J Hum Genet 89: 308-312. [Crossref]

21. Montenegro G, Powell E, Huang J, Speziani F, Edwards YJ, et al. (2011) Exome sequencing allows for rapid gene identification in a Charcot-Marie-Tooth family. Ann Neurol 69: 464-470. [Crossref]

22. Montenegro G, Powell E, Huang J, Speziani F, Edwards YJ, et al. (2011) Exome sequencing allows for rapid gene identification in a Charcot-Marie-Tooth family. Ann Neurol 69: 464-470. [Crossref]

23. Hong YB, Joo J, Hyun YS, Kwak G, Choi YR, et al. (2016) A mutation in PMP2 causes dominant demyelinating Charcot-Marie-Tooth neuropathy. PLoS Genet 12: e1005829. [Crossref]

24. Kennerson ML, Kim EJ, Siddell A, Kidambi A, Kim SM, et al. (2016) X-linked Charcot-Marie-Tooth disease type 6 (CMTX6) patients with a p.R158H mutation in the pyruvate dehydrogenase kinase isoenzyme 3 gene. J Periph Nerv Syst [Crossref]

25. Ghaoui R, Palmio J, Brewer J, Lek M, Needham M, et al. (2016) Mutations in HSPB8 causing a new phenotype of distal myopathy and motor neuropathy. Neurology 86 : 391-398. [Crossref]

26. Shashi V, Zunich J, Kelly TE, Fryburg JS (1995) Neuroectodermal (CHIME) syndrome an additional case with long term follow up of all reported cases. J Med Genet 32: 465 469. [Crossref]

27. Srour M, Schwartzentruber J, Hamdan FF, Ospina LH, Patry L, et al. (2012) Mutations in C5ORF42 cause Joubert syndrome in the French Canadian population. Am J Hum Genet 90: 693-700. [Crossref]

28. Srour M, Hamdan FF, McKnight D, Davis E, Mandel H, et al. (2015) Joubert Syndrome in French Canadians and Identification of Mutations in CEP104. Am J Hum Genet 97: 744-753. [Crossref]

29. Schossig A, Wolf NI, Fischer C, Fischer M, Stocker G, et al. (2012) Mutations in ROGDI Cause Kohlschütter-Tönz Syndrome. Am J Hum Genet 90: 701-707. [Crossref]

30. Edvardson S, Cinnamon Y, Jalas C, Shaag A, Maayan C, et al. (2012) Hereditary sensory autonomic neuropathy caused by a mutation in dystonin. Ann Neurol 71: 569572. [Crossref]

31. Rivière JB, van Bon BW, Hoischen A, Kholmanskikh SS, O'Roak BJ, et al. (2012) De novo mutations in the actin genes ACTB and ACTG1 cause Baraitser-Winter syndrome. Nat Genet 44: 440-444, S1-2. [Crossref]

32. Vissers LE, de Ligt J, Gilissen C, Janssen I, Steehouwer M, et al. (2010) A de novo paradigm for mental retardation. Nat Genet 42: 1109-1112. [Crossref]

33. Papandreou A, McTague A, Trump N, Ambegaonkar G, et al. (2015) GABRB3 mutations: a new and emerging cause of early infantile epileptic encephalopathy. Dev Med Child Neurol . [Crossref]

34. Anttonen AK, Hilander T, Linnankivi T, Isohanni P, French RL, et al. (2015) Selenoprotein biosynthesis defect causes progressive encephalopathy with elevated lactate. Neurology 85: 306-315. [Crossref]

35. Woolf AD, Pfleger B (2003) Burden of major musculoskeletal conditions. Bull World Health Organ 81: 646-656. [Crossref]

36. Becker J, Semler O, Gilissen C, Li Y, Bolz HJ, et al. (2011) Exome sequencing identifies truncating mutations in human SERPINF1 in autosomal-recessive osteogenesis imperfecta. Am J Hum Genet 88: 362-371. [Crossref]

37. Glazov EA, Zank1 A, Donskoi M, Kenna TJ, Thomas GP, et al. (2011) Whole-exome 
re-sequencing in a family quartet identifies POP1 mutations as the cause of a novel skeletal dysplasia. PLoS Genet 7: e1002027. [Crossref]

38. Zhang Z, Zhang C, Zhang Z (2013) Primary hypertrophic osteoarthropathy: an update. Front Med 7: 60-64. [Crossref]

39. Vissers LE, Lausch E, Unger S, Campos-Xavier AB, Gilissen C, et al. (2011) Chondrodysplasia and abnormal joint development associated with mutations in IMPAD1, encoding the Golgi-resident nucleotide phosphatase, gPAPP. Am J Hum Genet 88: 608-615. [Crossref]

40. Sobreira NL, Cirulli ET, Avramopoulos D, Wohler E, Oswald GL, et al. (2010) Wholegenome sequencing of a single proband together with linkage analysis identifies a Mendelian disease gene. PLoS Genet 6: e1000991. [Crossref]

41. Simpson MA, Irving MD, Asilmaz E, Gray MJ, Dafou D, et al. (2011) Mutations in NOTCH2 cause Hajdu-Cheney syndrome, a disorder of severe and progressive bone loss. Nat Genet 43: 303-305. [Crossref]

42. Marti-Masso JF, Ruiz-Martinez J, Makarov V, de Munain AL, Gorostidi A, et al (2012). Exome sequencing identiWes GCDH (glutaryl-CoA dehydrogenase) mutations as a cause of a progressive form of early-onset generalized dystonia. Human Genetics 131: $435-442$.

43. Alvarado DM, Buchan JG, Gurnett CA, Dobbs MB (2011) Exome sequencing identifies an MYH3 mutation in a family with distal arthrogryposis type 1.J Bone Joint Surg Am 93: 1045-1050. [Crossref]

44. Bernier FP, Caluseriu O, Ng S, Schwartzentruber J, Buckingham KJ, et al. (2012) Haploinsufficiency of SF3B4, a component of the pre-mRNA spliceosomal complex, causes Nager syndrome. Am J Hum Genet 90: 925-933. [Crossref]

45. Ghaoui R, Palmio J, Brewer J, Lek M, Needham M, et al. (2016) Mutations in HSPB8 causing a new phenotype of distal myopathy and motor neuropathy. Neurology 86: 391-398. [Crossref]

46. Watkins D, Schwartzentruber JA, Ganesh J, Orange JS, Kaplan BS, et al. (2011) Nove inborn error of folate metabolism: identification by exome capture and sequencing of mutations in the MTHFD1 gene in a single proband. J Med Genet 48: 590-592. [Crossref]

47. Calıșkan M, Chong JX, Uricchio L, Anderson R, Chen P, et al. (2011) Exome sequencing reveals a novel mutation for autosomal recessive non-syndromic mental retardation in the TECR gene on chromosome 19p13. Hum Mol Genet 20: 1285-1289. [Crossref]

48. Sanders SJ, Murtha MT, Gupta AR, Murdoch JD, Raubeson MJ, et al. (2012) De novo mutations revealed by whole-exome sequencing are strongly associated with autism. Nature 485: 237-241. [Crossref]

49. Hoischen A, van Bon BW, Rodríguez-Santiago B, Gilissen C, Vissers LE, et al. (2011) De novo nonsense mutations in ASXL1 cause Bohring-Opitz syndrome. Nat Genet 43 : 729-731. [Crossref]
50. Crawley JN, Heyer WD, LaSalle JM (2016) Autism and Cancer Share Risk Genes, Pathways, and Drug Targets. Trends Genet . [Crossref]

51. Bourgeron T (2015) From the genetic architecture to synaptic plasticity in autism spectrum disorder. Nat Rev Neurosci 16: 551-563. [Crossref]

52. Geschwind DH, State MW (2015) Gene hunting in autism spectrum disorder: on the path to precision medicine. Lancet Neurol 14: 1109-1120. [Crossref]

53. Schieving JH (2015) The role of exome sequencing in daily pediatric neurology practice. European J Paediatric Neurol 19: S47.

54. Srivastava S, Cohen JS, Vernon H, Barañano K, McClellan R, et al. (2014) Clinical whole exome sequencing in child neurology practice. Ann Neurol 76: 473-483. [Crossref]

55. Zhang T, Dutton-Regester K, Brown KM, Hayward NK (2016) The genomic landscape of cutaneous melanoma. Pigment Cell Melanoma Res . [Crossref]

56. Malhotra A, Levine S, Allingham-Hawkins D (2014) Whole exome sequencing for cancer - is there evidence of clinical utility? Advances in Genomics and Genetics 4: $115-128$.

57. Diamandis P, Ferrer-Luna R, Huang RY, Folkerth RD, Ligon AH, et al. (2016) Case Report: Next generation sequencing identifies a NAB2-STAT6 fusion in Glioblastoma. Diagn Pathol 11: 13. [Crossref]

58. Garrod AE (1923) Inborn errors of metabolism (2ndedtn.) Henry Frowde and Hodder \& Stoughton, London.

59. Bjursell MK, Blom HJ, Cayuela JA, Engvall ML, Lesko N, et al. (2011) Adenosine Kinase De?ciency disrupts the methionine cycle and causes hypermethioninemia encephalopathy, and abnormal liver function. Am J Hum Genet 89: 507-515. [Crossref]

60. Sloane JL, Johnston JJ, Manoli I, Chandler RJ, Krause C, et al. (2011). Exome sequencing identifies ACSF3 as the cause of Combined Malonic and Methylmalonic Aciduria. Nat Genet 43: 883-886. [Crossref]

61. Alfares A, Nunez LD, Al-Thihli K, Mitchell J, Melançon S, et al. (2011) Combined malonic and methylmalonic aciduria: exome sequencing reveals mutations in the ACSF3 gene in patients with a non-classic phenotype. J Med Genet 48: 602-605. [Crossref]

62. Meloche TM, Compton B, Rosario BH, Brown TL (2016) Alzheimer's disease pharmacotherapy, biomarkers and genetics. J Neurol Stroke 4: 00127.

63. Brown TL, Einstein GP, Tulp OL (2014) Dynamic stimulation of neurons by Sigma Photonic Quantum Energy as a novel biomarker for Alzheimer's Disease. J Lasers, Optics \& Photonics 1:3.

64. Weidner B, Bergquist N, Brown, TL (2016) Adult Night Terrors Since Childhood: A Case Report. J Neurol Neurophysiol 7: 1.

Copyright: (C2016 Brown TL. This is an open-access article distributed under the terms of the Creative Commons Attribution License, which permits unrestricted use, distribution, and reproduction in any medium, provided the original author and source are credited. 